\title{
Differences Between Women and Men Are Present in the Rate of Diagnosed Diseases After a Diagnostic Intervention is Conducted in Primary Care
}

\author{
Aranka V. Ballering, MSc, Judith G. M. Rosmalen, PhD, and \\ Tim C. olde Hartman, $M D, P h D$
}

Background: Recently it was shown that the relative lack of diagnostic interventions conducted in women mediated the negative association between female sex and diagnosed disease. However, it remains unknown whether women and men receive disease diagnoses in an equal frequency after diagnostic interventions have been performed in general practice.

Methods: We used generalized linear mixed-effect models to assess the association between diagnostic interventions and disease diagnoses when patients presented with common somatic symptoms and studied whether the association differed between female and male patients.

Results: In 34,268 episodes of care (61.4\% female) physical examinations and specialist referrals were associated with more disease diagnoses $(\mathrm{OR}=2.32$; $95 \% \mathrm{CI}=2.17-2.49$ and $\mathrm{OR}=1.38 ; 95 \%$ $\mathrm{CI}=1.27-1.49$, respectively), whereas laboratory diagnostics were associated with fewer disease diagnoses $(\mathrm{OR}=0.50 ; 95 \% \mathrm{CI}=0.47-0.54)$. Significant interaction terms showed that women presenting with back pain, tiredness, arm and/or leg symptoms and tingling extremities were provided with fewer disease diagnoses after diagnostic interventions were performed than men. We found no significant interaction term that indicated that men were provided with fewer disease diagnoses after a diagnostic intervention than women.

Conclusion: Especially when patients present with the mentioned symptoms, general practitioners should be aware that diagnostic interventions yield fewer disease diagnoses in female patients than in men. Yet, performing fewer diagnostic interventions in women with these symptoms will further exacerbate sex differences in disease diagnoses. ( $\mathrm{J}$ Am Board Fam Med 2022;35:73-84.)

Keywords: Episode of Care, Gender Differences, Medically Unexplained Symptoms, Primary Health Care

\section{Background}

Multiple studies have shown that female patients' common somatic symptoms remain more often medically unexplained than male patients' somatic symptoms. ${ }^{1,2}$ Yet, only recently it has been shown that the negative association between female sex

This article was externally peer reviewed.

Submitted 13 July 2021; revised 7 October 2021; accepted 8 October 2021.

From University of Groningen, University Medical Center of Groningen, Interdisciplinary Center Psychopathology and Emotion Regulation (ICPE), Groningen, the Netherlands. P. O. Box 30.001, 9700 RB, Groningen, the Netherlands (AVB, JGMR); Department of Primary and Community Care, Radboud University Medical Center, Nijmegen, the Netherlands. P.O. Box 9101, 6500 HB, Nijmegen, the Netherlands (TCOH)

Funding: This work was supported by the ZonMw Gender and Health program (project number 849200013).

Conflict of interest: The authors have no competing interests to report. and medically unexplained symptoms is mediated by the performed diagnostic interventions in primary care. ${ }^{3}$

Recent studies show that differences between women and men in primary care diagnostic trajectories for somatic symptoms are not uncommon. A study that followed patients from common somatic complaint presentation to final diagnosis has shown that women receive fewer physical examinations, less diagnostic imaging, and fewer referrals to a

Ethical approval: Studies involving FaMe-Net data are exempted from ethical review by the CCMO (Dutch Central Committee on research involving human subjects).

Corresponding author: Aranka V. Ballering, MSc, Interdisciplinary Center Psychopathology and Emotion Regulation (ICPE), Groningen, the Netherlands. P.O. Box 30.001, Internal code CC72, 9700 RB, Groningen, the Netherlands (E-mail: a.v.ballering@umcg.nl). 
specialist than men when they present with common somatic symptoms in general practice. ${ }^{3}$ A similar pattern is observed when patients present with cough and/or shortness of breath in general practice. $^{4}$ In addition, female patients who present symptoms suggestive of coronary heart disease have a lower likelihood of receiving a physical examination that follows the guidelines, 5 and of being referred to a cardiologist ${ }^{7}$ than male patients.

Little to no research focused on whether these sex differences in the rate of diagnostic interventions in patients presenting somatic symptoms are justified, as it has not yet been studied whether women and men receive disease diagnoses in an equal frequency after diagnostic interventions have been performed in general practice. In other words, it remains unknown whether a diagnostic intervention in general practice, such as physical examinations, diagnostic imaging, laboratory diagnostics, or referrals to a specialist, associates differently in women and men with a disease diagnosis (ie, with explained symptoms).

Clinically, to ensure equal and appropriate care for all patients, irrespective of a patient's sex, it is pivotal for general practitioners (GPs) to be aware of whether the odds of receiving a disease diagnosis after a certain diagnostic intervention differs significantly between male and female patients presenting with somatic symptoms. Therefore, the aim of this study is to assess whether differences between men and women are present in the association between diagnostic interventions and a disease diagnosis when patients present themselves with common somatic symptoms. In this study data derived from the Dutch Family Medicine Network (FaMe-Net), a practice-based research network, is analyzed by generalized linear mixed-effect models.

\section{Methods}

\section{Study Design}

Our study included data from the FaMe-Net, in which approximately 32,000 patients from 26 GPs working in seven general practices throughout the Netherlands are included. ${ }^{8}$ FaMe-Net is the world's oldest practice-based research network and has registered patients' morbidity in an episode of care (EoC) structure since its inception. GPs systematically code all information, including reason for encounter (RFE), interventions (ie, physical examinations, laboratory diagnostics, diagnostic imaging, and referrals to specialists), and final diagnoses, according to the International Classification of Primary Care (ICPC-2). An EoC is defined as a patient's health problem from the first encounter with the GP until the last encounter related to that specific health problem.

Although an EoC can start with multiple RFEs, one final diagnosis is ultimately linked to all encounters within an EoC. A final diagnosis could be either a disease diagnosis or symptom diagnosis. A disease diagnosis was defined as symptoms, followed over time, that evolve in a diagnosed disease (operationalized as ICPC $\geq 70$, including psychiatric ICPC codes), whereas a symptom diagnosis was defined as symptoms, when followed over time, that continued to be symptoms as relevant diagnostic criteria were not met (operationalized as ICPC $<30$ ). The RFE of an EoC should be acknowledged by patients as an adequate description of their demand of care and can be a symptom, a self-diagnosis, or a request for a particular intervention. The quality of data registration within FaMe-Net is high, as participating GPs regularly meet to discuss registration logistics and diagnostic criteria. ${ }^{8}$ Moreover, the automated GP information system recognizes errors and inconsistencies in registration.

For this study, we selected EoCs that started with a common somatic symptom between January 1, 2014 and December 31, 2018. Contacts within an EoC that continued after this date were not included. Face-to-face encounters as well as telephone and digital consultations were included. We included 15 RFEs related to 12 symptoms: headache (ICPC-N01), dizziness (ICPC-N17), heart pain (ICPC-K01), (lower) back pain (ICPC-L02 and ICPC-L03), nausea (ICPC-D09), muscle pain (ICPC-L18), shortness of breath/dyspnea (ICPCR02), chills (ICPC-A02), tingling of fingers, feet, and/or toes (ICPC-N05), swallowing/throat problems (ICPC-D21 and ICPC-R21), weakness or general tiredness (ICPC-A04), and arm or leg symptoms (ICPC-L09 and ICPC-L14). These 12 symptoms reflect the contents of the Symptom Checklist-90 Somatization subscale (SCL-90 SOM), ${ }^{9}$ are common, ${ }^{10}$ and often remain unexplained. ${ }^{11}$ All EoC that started with the same RFE on the same date within the same patient were excluded $(n=106)$. When the EoC started with more than one of the included RFEs ( $n=1605 ; 4.7 \%$ ), we analyzed the first-mentioned RFE. 


\section{Statistical Analyses}

To assess whether diagnostic interventions, namely, physical examinations (ICPC-30 and ICPC-31), laboratory diagnostic interventions (ICPC-33 and ICPC-34), diagnostic imaging (ICPC-41), and specialist referrals (ICPC-67) were associated with a disease diagnosis, we defined generalized linear mixed-effect models. EoCs are nested within an individual, thus we clustered analyses at the patient level. Patients' sex, patients' age at time of diagnosis, the number of contacts between a patient and GP during an EoC, type of consult (face-to-face, digital, or by phone), the type of RFE, the presence of comorbidities at the start of an EoC (Appendix 1) and the four aforementioned diagnostic interventions were included as independent variables. In addition, we included interaction terms between patient's sex and the diagnostic interventions to assess whether the association between the respective diagnostic intervention and disease diagnosis differed between female and male patients.

To test whether the continuous covariates (patients' age and number of contacts between a patient and GP within an EoC) included in the analyses fulfilled the linearity assumption of multiple logistic regression, we divided the covariates into categories and assessed whether the estimates changed monotonically. In addition, we found no indication for multicollinearity, as the variance inflation factor was $<5$ in all analyses. ${ }^{12}$ The statistical analyses and descriptive analyses, including chi square tests, Mann Whitney $U$ test, and independent $t$-test were conducted in IBM SPSS Statistics v. 25. We maintained a two-sided $\alpha$-value of $P<.01$ to correct for multiple testing. We adhered to the STROBE and SAGER guidelines for reporting observational cohort studies. ${ }^{13}$

\section{Results}

We identified 34,268 EoCs that started with a common somatic symptom in 10,541 female patients and 7,915 male patients. The majority of these EoCs started with $1 \mathrm{RFE}(71.7 \%)$, and most EoCs only involved 1 encounter with the GP (65.1\%). A more detailed overview of the study population is provided in Table 1.

Table 1. Overview of the Study Population

\begin{tabular}{|c|c|c|c|}
\hline Characteristic & Female & Male & $P$ Value \\
\hline Patients, $\mathrm{n}$ & $10,541(57.1 \%)$ & $7,915(42.9 \%)$ & \\
\hline Patients' age in years, mean (SD) & $43.4(23.1)$ & $42.3(23.9)$ & $<0.001^{\S}$ \\
\hline Patient years, ${ }^{*} \mathrm{n}$ & $78,954(52.3 \%)$ & $75,734(47.7 \%)$ & \\
\hline Unique $\mathrm{EoC}, \mathrm{n}$ & $21,025(61.4 \%)$ & $13,243(38.6 \%)$ & \\
\hline \multicolumn{4}{|l|}{ EoC with intervention } \\
\hline No intervention & $3,218(15.3 \%)$ & $1,827(13.8)$ & \\
\hline$\geq 1$ intervention & $17,807(84.7 \%)$ & $11,416(86.2 \%)$ & $<0.001^{\dagger}$ \\
\hline \multicolumn{4}{|l|}{ EoC with final diagnosis } \\
\hline Disease diagnosis & $7,470(35.5 \%)$ & $4,924(37.2 \%)$ & $0.002^{\dagger}$ \\
\hline Symptom diagnosis & $13,555(64.5 \%)$ & $8,319(62.8 \%)$ & \\
\hline \multicolumn{4}{|l|}{ Encounters within an EoC } \\
\hline 1 encounter & $13,619(64.8 \%)$ & $8,697(65.7 \%)$ & $0.090^{\dagger}$ \\
\hline$>1$ encounter & $7,406(35.2 \%)$ & $4,546(34.3 \%)$ & \\
\hline \multicolumn{4}{|l|}{ RFE per EoC } \\
\hline $1 \mathrm{RFE}$ & $14,739(70.1 \%)$ & $9,839(74.3 \%)$ & $<0.001^{\dagger}$ \\
\hline$>1 \mathrm{RFE}$ & $6,286(29.9 \%)$ & $3,404(25.7 \%)$ & \\
\hline EoC with comorbidities, $\mathrm{n}$ & $8,282(39.4 \%)$ & $5,295(43.7 \%)$ & $0.271^{\dagger}$ \\
\hline Cardiovascular disease & $5,741(27.3 \%)$ & $3,827(28.9 \%)$ & $0.001^{\dagger}$ \\
\hline Asthma and/or COPD & $3,106(14.8 \%)$ & $1,998(15.1 \%)$ & $0.427^{\dagger}$ \\
\hline Malignancies & $1,684(8.0 \%)$ & $979(7.4 \%)$ & $0.038^{\dagger}$ \\
\hline
\end{tabular}

Abbreviations: COPD, chronic obstructive pulmonary disease; EoC, episode of care; RFE, reason for encounter; SD, standard deviation.

*The cumulative years included patients were at risk of an incident common somatic symptom.

${ }^{\dagger} \chi^{2}$ test.

${ }^{\$}$ Independent $t$-test. 
Figure 1. Relative frequency of the performed interventions in female and male episodes of care related to common somatic symptoms ( $* P<.001, \chi^{2}$ test). Abbreviation: EoC, episode of care.

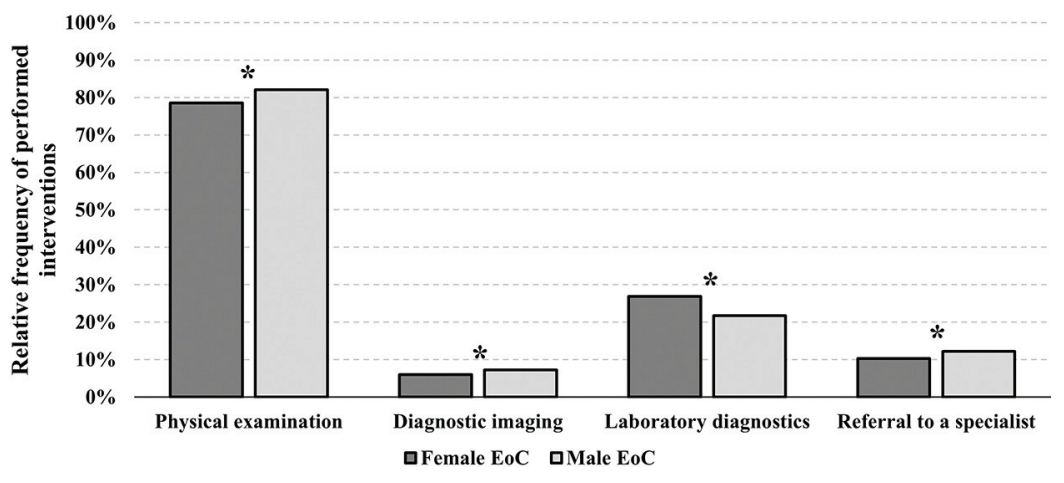

\section{Sex Differences in Performed Diagnostic Interventions}

Figure 1 shows that three diagnostic interventions performed by the GP to obtain a diagnosis are significantly more often performed per EoC in male than in female patients. Only laboratory diagnostics are more often performed in female EoC. Appendix 2 shows the frequencies of the performed interventions stratified by sex and RFE.

\section{Sex Differences in Outcomes of Diagnostic Interventions}

Table 2 shows that the odds of receiving a disease diagnosis were signficantly higher in EoCs in which a physical examination was performed (odds ratio $[\mathrm{OR}]=2.32$, 95\% CI, 2.17-2.49) or when the GP requested a referral to a specialist $(\mathrm{OR}=1.38,95 \%$ CI, 1.27-1.49). In contrast, a request for laboratory diagnostics increased the odds of a symptom diagnosis $(\mathrm{OR}=0.50,95 \% \mathrm{CI}, 0.47-0.54)$.

We found a significant interaction term between sex and laboratory diagnostics $(\mathrm{OR}=0.82,95 \% \mathrm{CI}$,
0.73-0.93), as well as a significant sex-by-specialist referral interaction term $(\mathrm{OR}=0.84,95 \% \mathrm{CI}, 0.72$ 0.97). These estimates indicate that if a GP requests laboratory diagnostics or a specialist referral, the odds of receiving a disease diagnosis are significantly lower for female patients than for male patients.

\section{Sex Differences in Outcomes of Diagnostic Interventions per RFE}

Table 3 shows in more detail which diagnostic interventions associate with a disease diagnosis, stratified per RFE. For example, in (lower) back pain, it was found that all diagnostic interventions, except for imaging, are associated with a disease diagnosis. In addition, in the patients with (lower) back pain we found significant interaction terms between patients' sex and physical examinations $(\mathrm{OR}=0.51,95 \% \mathrm{CI}$, $0.34-0.78)$, patients' sex and imaging $(\mathrm{OR}=0.64$, 95\% CI, 0.43-0.96), and patients' sex and a specialist referral $(\mathrm{OR}=0.46,95 \%$ CI, 0.29-0.72). This

Table 2. Adjusted Associations Between Diagnostic Interventions and Disease Diagnoses in Episodes of Care Starting with Common Somatic Symptoms, Stratified by Sex

\begin{tabular}{|c|c|c|c|}
\hline \multirow[b]{2}{*}{ Independent Variables } & \multicolumn{3}{|c|}{ Odds Ratio $(95 \% \mathrm{CI})^{*}$} \\
\hline & Total EoC $(n=34,268)$ & Female EoC $(n=21,025)$ & Male $\operatorname{EoC}(\mathrm{n}=13,243)$ \\
\hline Physical examination & $2.32(2.17-2.49)$ & $2.33(2.14-2.54)$ & $2.32(2.07-2.60)$ \\
\hline Laboratory diagnostics $^{\dagger}$ & $0.50(0.47-0.54)$ & $0.47(0.44-0.52)$ & $0.56(0.50-0.62)$ \\
\hline Imaging & $0.96(0.86-1.06)$ & $0.92(0.81-1.06)$ & $1.00(0.85-1.17)$ \\
\hline Referral to a specialist $^{\dagger}$ & $1.38(1.27-1.49)$ & $1.29(1.17-1.43)$ & $1.50(1.33-1.69)$ \\
\hline
\end{tabular}

Abbreviations: EoC, episode of care; RFE, reason for encounter; CI, confidence interval.

*Adjusted for patients' sex (total EoC), patients' age, presence of comorbidities at the start of an EoC, number of contacts within an EoC, type of consult, and type of RFE.

${ }^{\dagger}$ The interaction term between the patient's sex and the respective diagnostic intervention was statistically significant. 
Table 3. Adjusted Odds Ratios and Significant Intervention-by-Female-Sex Interaction Terms for the Association Between Diagnostic Interventions and Disease Diagnosis, Stratified by Reason for Encounter

\begin{tabular}{|c|c|c|c|c|}
\hline & \multicolumn{4}{|c|}{$\mathrm{OR}^{*}(95 \% \mathrm{CI})$} \\
\hline & $\begin{array}{l}\text { Headache } \\
(\mathrm{n}=3,411)\end{array}$ & $\begin{array}{l}\text { Dizziness } \\
(\mathrm{n}=2,709)\end{array}$ & $\begin{array}{l}\text { Heart Pain } \\
(\mathrm{n}=660)\end{array}$ & $\begin{array}{c}\text { (Lower) Back Pain } \\
\quad(\mathrm{n}=5,962)\end{array}$ \\
\hline Physical examination & $2.07(1.74-2.47)$ & $2.12(1.68-2.67)$ & $0.98(0.59-1.64)$ & $1.35(1.11-1.63)^{\dagger}$ \\
\hline Laboratory diagnostics & $0.59(0.47-0.74)$ & $0.30(0.25-0.37)$ & $0.94(0.56-1.58)$ & $1.49(1.18-1.88)$ \\
\hline Imaging & $0.67(0.37-1.22)$ & $0.43(0.14-1.36)$ & $0.51(0.12-2.23)$ & $0.87(0.70-1.07)^{\dagger}$ \\
\hline \multirow[t]{3}{*}{ Specialist referral } & $0.77(0.60-0.98)$ & $1.11(0.84-1.46)$ & $1.14(0.73-1.77)^{\dagger}$ & $2.78(2.18-3.55)^{\dagger}$ \\
\hline & \multicolumn{4}{|c|}{$\mathrm{OR}^{*}(95 \% \mathrm{CI})$} \\
\hline & $\begin{array}{l}\text { Nausea } \\
(\mathrm{n}=1,222)\end{array}$ & $\begin{array}{l}\text { Muscle Pain } \\
(\mathrm{n}=554)\end{array}$ & $\begin{array}{l}\text { Shortness of Breath } \\
\qquad(\mathrm{n}=3,593)\end{array}$ & $\begin{array}{l}\text { Chills } \\
(\mathrm{n}=132)\end{array}$ \\
\hline Physical examination & $1.93(1.46-2.56)$ & $1.19(0.71-2.01)$ & $2.58(2.02-3.31)$ & $3.35(1.23-9.11)$ \\
\hline Laboratory diagnostics & $0.49(0.35-0.68)$ & $0.71(0.41-1.23)$ & $0.78(0.65-0.92)$ & $0.81(0.29-2.28)$ \\
\hline Imaging & $0.57(0.26-1.21)$ & $0.30(0.06-1.39)$ & $0.49(0.38-0.64)$ & $0.69(0.02-19.9)$ \\
\hline \multirow[t]{3}{*}{ Specialist referral } & $1.25(0.82-1.90)$ & $0.66(0.27-1.59)$ & $1.07(0.87-1.31)$ & $0.57(0.19-1.74)$ \\
\hline & \multicolumn{4}{|c|}{$\mathrm{OR}^{*}(95 \% \mathrm{CI})$} \\
\hline & $\begin{array}{l}\text { Tingling in Fingers, } \\
\text { Feet, and/or Toes }(\mathrm{n}=609)\end{array}$ & $\begin{array}{l}\text { Swallowing/Throat } \\
\text { Symptoms }(\mathrm{n}=4,961)\end{array}$ & $\begin{array}{l}\text { Weakness/General } \\
\text { Tiredness }(\mathrm{n}=5,608)\end{array}$ & $\begin{array}{c}\text { Arm and/or Leg } \\
\text { Symptoms }(n=4,847)\end{array}$ \\
\hline Physical examination & $1.16(0.72-1.87)$ & $5.42(4.56-6.44)$ & $2.57(2.14-3.09)$ & $1.70(1.40-2.06)$ \\
\hline Laboratory diagnostics & $0.40(0.25-0.64)^{\dagger}$ & $0.97(0.80-1.18)$ & $0.20(0.18-0.24)^{\dagger}$ & $0.51(0.41-0.63)^{\dagger}$ \\
\hline Imaging & $0.47(0.11-2.06)$ & $0.40(0.23-0.72)$ & $1.62(1.14-2.32)$ & $1.11(0.93-1.32)$ \\
\hline Specialist referral & $1.72(1.05-2.81)$ & $0.64(0.51-0.81)$ & $1.25(0.99-1.58)$ & $1.86(1.55-2.23)^{\dagger}$ \\
\hline
\end{tabular}

Abbreviations: EoC, episode of care; OR, odds ratio; CI, confidence interval.

*Adjusted for the patients' age at diagnosis, comorbidities, number of contacts per EoC, and sex. †Significant intervention-byfemale-sex interaction term.

indicates that female patients with lower back pain received significantly fewer disease diagnoses after they underwent these diagnostic interventions than their male counterparts.

Similarly, in EoCs starting with tingling sensations in extremities, with tiredness, or with arm and/or leg symptoms, we found that receiving laboratory diagnostics was associated with fewer disease diagnoses (Table 3). In these EoCs, significant interaction terms between patients' sex and laboratory diagnostics $(\mathrm{OR}=0.32,95 \% \mathrm{CI}, 0.13-0.81 ; \mathrm{OR}=0.72,95 \% \mathrm{CI}$, $0.53-0.96$; OR $=0.56,95 \% \mathrm{CI}, 0.37-0.86$, respectively) were found as well (Appendix 3). These indicate that female patients who were provided with laboratory diagnostics upon presenting these complaints less frequently received a disease diagnosis than male patients with these complaints that received laboratory diagnostics. All significant interaction terms between female sex and the respective diagnostic interventions indicated that women are less likely diagnosed with a disease after being provided with a diagnostic intervention than men. An overview of all statistically significant interaction terms between sex and a diagnostic intervention stratified by RFE is given in Appendix 3.

\section{Discussion}

This study is the first to show that diagnostic interventions are differently associated with disease diagnoses in female and male patients presenting with common somatic symptoms in general practice. Women receive fewer disease diagnoses than men after a diagnostic intervention; for example, in (lower) back pain men more often receive a disease diagnosis after a physical examination, imaging, and a specialist referral than women. Similarly, when laboratory diagnostics are performed, male patients 
with tingling fingers, feet, and/or toes, tiredness, and arm and/or leg symptoms more often receive a disease diagnosis than female patients.

\section{Limitations and Strengths}

Results of this study should be interpreted in the light of its limitations. First, patients' full medical history was unknown, and the adjustment for comorbidities is nonexhaustive as it included asthma/chronic obstructive pulmonary disease, cardiovascular disease, and malignancies. Second, not all patient characteristics that may affect the association between diagnostic interventions and final diagnosis were known, including patients' socioeconomic status, ethnicity, and time before seeking help. Third, the sex and gender of the involved GPs is unknown. Concordance between a patient's and GP's sex is important in patients' diagnostic trajectories. Female physicians, for instance, are more inclined to conduct female preventive procedures than male physicians. ${ }^{14,15}$ Male patients have also been found to be more demanding and assertive toward their GP than female patients, ${ }^{16}$ an effect that is amplified in case of female GPs. ${ }^{17}$

This study also has strengths. First, the data were extracted from a long-lasting, large primary care registration network, which minimizes the risk of recall bias. FaMe-Net is the only existing database in which GPs register the RFE, diagnoses, and conducted interventions for all contacts within an EoC. The data are detailed, valid, and accurate, as participating GPs frequently discuss diagnostic coding. ${ }^{8}$ Furthermore, the use of RFEs to identify EoCs related to common somatic symptoms reduces bias in the data, as it avoids the GPs' interpretation of a patient's complaint. ${ }^{18}$

\section{Comparison to Literature}

In line with previous research, we found that fewer diagnostic interventions were conducted in female EoCs, except for laboratory diagnostics. ${ }^{4-6}$ For example, one of these former studies focusing on cough and dyspnea showed that women with these complaints are less likely to be provided with diagnostic interventions and a disease diagnosis compared with their male counterparts. This could be due to possible sex-related differences in help-seeking behavior. ${ }^{19}$ Seeking help early in the disease process may result in women presenting less typical symptoms for which the GP does not perform or request diagnostic interventions. Ultimately, this may result in underdiagnosis in female patients.
However, the diagnosis of a disease is not necessarily a direct indicator of improved care.

In addition, it has been argued that fewer physical examinations in female patients may be due to GPs' concerns about the shame that female patients may experience during a physical examination, leading to hesitance in GPs to examine, for example, intimate areas. ${ }^{20}$ Others have argued that the abundance of male-bodied images in medical anatomy textbooks results in a sex bias in physical examinations. ${ }^{21}$

However, in female EoCs more laboratory diagnostics were ordered than in male EoCs. This may be due to uncertainty, either in the GP or in the patient. The GP may experience diagnostic uncertainty in female patients, which may interact with anticipated regret of missing a serious disease. ${ }^{22,23}$ Especially laboratory diagnostics were found to associate with mitigating diagnostic uncertainty in GPs. ${ }^{23}$ Notably, previous research on sex differences in diagnostic uncertainty of the GP focused on cardiovascular disease and found a greater diagnostic uncertainty among GPs when assessing female patients; ${ }^{22,24}$ whether this occurs in common somatic symptoms in general practice as well has not been investigated yet. Female patients may experience uncertainty about the explanation of symptoms given by the GP, possibly due to their heightened tendency to ruminate. ${ }^{25}$ As laboratory diagnostic tests are often used as a means to reassure patients and more easily applied than imaging or specialist referrals, ${ }^{23}$ GPs may be more inclined to order laboratory diagnostic tests to reassure female patients.

We also show that women received fewer disease diagnoses than men after diagnostic interventions were conducted. This is in line with two recent studies in the field of cardiovascular medicine, one of which investigated sex-based differences in noninvasive diagnostic methods for coronary artery disease in establishing disease in men and women. In this study, women were found to have more normal diagnostic tests than men when presenting symptoms. ${ }^{26}$ The other study assessed whether angiographies resulted in sex differences in disease outcome in patients with suspected coronary heart disease. It was found that compared with men, women had a higher likelihood of having no coronary heart disease after undergoing a computed tomography coronary angiography. ${ }^{27}$ To the authors' knowledge, no studies assess sex differences in receiving a 
disease diagnosis after diagnostic interventions were conducted when presenting with common somatic symptoms in general practice.

The current results are also in line with studies that report an increased female prevalence and incidence of functional somatic syndrome diagnoses in general practice. ${ }^{11}$ A symptom diagnosis, in which symptoms continue to be symptoms over time, is only to be given if an adequate medical examination and anamnesis has not revealed a condition that explains the symptoms. ${ }^{1,28,29}$ The adequate medical examination comprises diagnostic interventions as discussed here. Thus, if female patients receive relatively more symptom diagnoses, diagnostic interventions relate to fewer disease diagnoses in women.

\section{Clinical Implications}

This study shows that differences between women and men are present in the association between diagnostic interventions and disease diagnosis: female patients receive fewer disease diagnoses than male patients after a diagnostic intervention is conducted. Especially in (lower) back pain, tingling fingers, feet, and/or toes, tiredness, and arm and/or leg symptoms, a diagnostic intervention more often yields a disease diagnosis in male patients than in female patients.

At face value, this may point toward a justification of the fewer diagnostic interventions that are performed by the GP in female patients. After all, the odds of receiving a disease diagnosis after an intervention are lower in women than in men. However, recent research also found that the association between female sex and disease diagnosis is mediated by these diagnostic interventions. ${ }^{3}$ Although GPs cannot alter whether diagnostic interventions detect disease in women, GPs can increase their rate of diagnostic interventions conducted in women, to avoid underdiagnosis in female patients. Therefore, reducing the use of diagnostic interventions in women even further is unwarranted, as fewer diagnostic interventions in female patients may further exacerbate the difference in disease diagnosis between men and women. Nevertheless, requesting more diagnostic interventions in women should be done with caution, as diagnostic interventions may cause iatrogenic harm.

Furthermore, as women are thought to seek help earlier in their disease process than men, they may present with more atypical complaints in general practice. These pose a challenge to diagnose, as the symptoms may have not yet progressed enough to be readily attributed to an organic disease, or diagnostic interventions may not be sensitive enough to detect disease. Therefore, further research could focus on sex differences in help-seeking behavior for common somatic symptoms.

In addition, this study could not account for possible underdiagnosis in women. However, it is suggested that the use of sex-specific thresholds for diagnostic interventions, as is done with troponin I for example, may increase the sensitivity of detecting ischemic heart disease. ${ }^{30}$ Thus, further investigations could assess whether diagnostic interventions have a similar diagnostic accuracy in detecting disease or abnormalities in male and female patients presenting with common somatic symptoms.

Unfortunately, our study does not lead to clinical implications that directly result in changes in patient care. The data used in this study do not suffice for that purpose, since a disease diagnosis is not a direct indicator of improved patient care. To formulate a call to action for optimal gender-sensitive patient care in a concrete and evidence-based manner, the current study should be complemented with studies that assess the aforementioned help seeking for somatic symptoms and sex-specific diagnostic accuracy for diagnostic interventions in detail. Furthermore, studies that focus on gender-sensitive medicine from the patient's perspective are needed as well. This study functions as a first exploration into possible gender inequities in the primary care process for common somatic symptoms.

To see this article online, please go to: http://jabfm.org/content/ 35/1/73.full.

\section{References}

1. Evangelidou S, NeMoyer A, Cruz-Gonzalez M, O'Malley I, Alegria M. Racial/ethnic differences in general physical symptoms and medically unexplained physical symptoms: Investigating the role of education. Cultur Divers Ethnic Minor Psychol 2020;26:557-69.

2. Dirkzwager AJ, Verhaak PF. Patients with persistent medically unexplained symptoms in general practice: characteristics and quality of care. BMC Fam Pract 2007;8:33.

3. Ballering AV, Muijres D, Uijen AA, Rosmalen JGM, Olde Hartman TC. Sex differences in the diagnostic trajectories and final diagnosis of patients presenting with common somatic symptoms in primary care. J Psychosomatic Research. Forthcoming. 
4. Groeneveld JM, Ballering AV, van Boven $\mathrm{K}$, Akkermans RP, Olde Hartman TC, Uijen AA. Sex differences in incidence of respiratory symptoms and management by general practitioners. Fam Pract 2020;37:631-6.

5. Arber S, McKinlay J, Adams A, Marceau L, Link C, O'Donnell A. Patient characteristics and inequalities in doctors' diagnostic and management strategies relating to CHD: a video-simulation experiment. Soc Sci Med 2006;62:103-15.

6. McKinlay JB, Link CL, Freund KM, Marceau LD, O'Donnell AB, Lutfey KL. Sources of variation in physician adherence with clinical guidelines: results from a factorial experiment. J Gen Intern Med 2007;22:289-96.

7. Clerc Liaudat C, Vaucher P, De Francesco T, et al. $\mathrm{Sex} /$ gender bias in the management of chest pain in ambulatory care. Womens Health (Lond) 2018; 14:1745506518805641.

8. Luijks H, van Boven K, Olde Hartman T, Uijen A, van Weel C, Schers H. Making visible what is intuitively known by family physicians: capturing core value of family medicine in structured data. J Am Board Fam Med. Forthcoming.

9. Zijlema WL, Stolk RP, Löwe B, Rief W, White PD, Rosmalen JGM, BioSHaRE. How to assess common somatic symptoms in large-scale studies: a systematic review of questionnaires. J Psychosom Res 2013;74:459-68.

10. Acevedo-Mesa A, Tendeiro JN, Roest A, Rosmalen JGM, Monden R. Improving the measurement of functional somatic symptoms with item response theory. Assessment 2021;28:196070:1073191120947153.

11. Verhaak PF, Meijer SA, Visser AP, Wolters G. Persistent presentation of medically unexplained symptoms in general practice. Fam Pract 2006;23: 414-20.

12. Miles J, Shevlin M. Collinearity. In: Applying regression and correlation: A guide for students and researchers. Los Angeles (CA): Sage; 2001. p. 126-35.

13. Heidari S, Babor TF, De Castro P, Tort S, Curno $M$. Sex and gender equity in research: rationale for the SAGER guidelines and recommended use. Res Integr Peer Rev 2016;1:2.

14. Vinker S, Kvint I, Erez R, Elhayany A, Kahan E. Effect of the characteristics of family physicians on their utilisation of laboratory tests. Br J Gen Pract 2007;57:377-82.

15. Bertakis KD, Azari R. Patient gender and physician practice style. J Womens Health (Larchmt) 2007; 16:859-68.

16. Roter DL, Hall JA, Aoki Y. Physician gender effects in medical communication: a meta-analytic review. JAMA 2002;288:756-64.
17. Hall JA, Irish JT, Roter DL, Ehrlich CM, Miller LH. Gender in medical encounters: an analysis of physician and patient communication in a primary care setting. Health Psychology 1994;13:384-92.

18. van Boven K, Uijen AA, van de Wiel N, Oskam SK, Schers HJ, Assendelft WJJ. The diagnostic value of the patient's reason for encounter for diagnosing cancer in primary care. J Am Board Fam Med 2017;30:806-12.

19. Barsky AJ, Peekna HM, Borus JF. Somatic symptom reporting in women and men. J Gen Intern Med 2001;16:266-75.

20. Chakkalakal RJ, Higgins SM, Bernstein LB. Does patient gender impact resident physicians' approach to the cardiac exam? J Gen Intern Med 2013;28: 561-6.

21. Parker R, Larkin T, Cockburn J. A visual analysis of gender bias in contemporary anatomy textbooks. Soc Sci Med 2017;180:106-13.

22. Michiels-Corsten M, Donner-Banzhoff N. Beyond accuracy: hidden motives in diagnostic testing. Fam Pract 2018;35:222-7.

23. van der Weijden T, van Bokhoven MA, Dinant GJ, van Hasselt CM, Grol RP. Understanding laboratory testing in diagnostic uncertainty: a qualitative study in general practice. Br J Gen Pract 2002;52: 974-80.

24. Lutfey KE, Link CL, Marceau LD, et al. Diagnostic certainty as a source of medical practice variation in coronary heart disease: results from a cross-national experiment of clinical decision making. Med Decis Making 2009;29:606-18.

25. Barsky AJ, Orav EJ, Bates DW. Somatization increases medical utilization and costs independent of psychiatric and medical comorbidity. JAMA Psychiatry 2005;62:903-10.

26. Pagidipati NJ, Coles A, Hemal K, et al. Sex differences in management and outcomes of patients with stable symptoms suggestive of coronary artery disease: insights from the PROMISE trial. Am Heart J 2019;208:28-36.

27. Mangion K, Adamson PD, Williams MC, et al. Sex associations and computed tomography coronary angiography-guided management in patients with stable chest pain. Eur Heart J 2020;41:1337-45.

28. Olde Hartman TC, Blankenstein AH, Molenaar AO, et al. NHG-standaard somatisch onvoldoende verklaarde lichamelijke klachten (SOLK). Huisarts Wet 2013;56:222-30.

29. Soler JK, Okkes I. Reasons for encounter and symptom diagnoses: a superior description of patients' problems in contrast to medically unexplained symptoms (MUS). Fam Pract 2012;29:272-82.

30. Humphries KH, Izadnegahdar M, Sedlak T, et al. Sex differences in cardiovascular disease-impact on care and outcomes. Front Neuroendocrinol 2017;46:46-70. 


\section{Appendix 1}

Table A1. Categorization of Comorbidities

\begin{tabular}{|c|c|c|c|}
\hline \multicolumn{2}{|r|}{ Malignancies } & \multicolumn{2}{|c|}{ Cardiovascular Disease } \\
\hline ICPC & Description & ICPC & Description \\
\hline A79 & Malignancy NOS & K72 & Cardiovascular neoplasm \\
\hline B72 & Hodgkin's disease/lymphoma & K74 & Ischemic heart dis w. angina \\
\hline B73 & Leukemia & K75 & Acute myocardial infarction \\
\hline B74 & Malig. neoplasm blood oth & K76 & Ischemic heart dis w/o angina \\
\hline B75 & Benign/unspec. neoplasm blood & K77 & Heart failure \\
\hline D74 & Malig. neoplasm stomach & K78 & Atrial fibrillation/flutter \\
\hline D75 & Malig. neoplasm colon/rectum & K79 & Paroxysmal tachycardia \\
\hline D76 & Malig. neoplasm pancreas & K80 & Cardiac arrhythmia NOS \\
\hline D77 & Malig. neoplasm digest oth/NOS & K81 & Heart/arterial murmur NOS \\
\hline F74 & Neoplasm of eye/adnexa & K82 & Pulmonary heart dis \\
\hline $\mathrm{H} 75$ & Neoplasm of ear & K83 & Heart valve dis NOS \\
\hline L71 & Malig. neoplasm musculoskeletal & K84 & Heart dis oth \\
\hline N74 & Malig. neoplasm nervous system & K86 & Hypertension uncomplicated \\
\hline N75 & Benign neoplasm nervous system & K87 & Hypertension complicated \\
\hline N76 & Neoplasm nervous system unspec. & K89 & Transient cerebral ischemia \\
\hline R84 & Malig. neoplasm bronchus/lung & K90 & Stroke/cerebrovascular accident \\
\hline R85 & Malig. neoplasm respiratory, oth & K91 & Cerebrovascular dis \\
\hline R92 & Neoplasm respiratory unspec. & K92 & Atherosclerosis/PVD \\
\hline $\mathrm{T} 71$ & Malig. neoplasm thyroid & & \\
\hline T73 & Neoplasm endocrine oth/unspec. & & ma and COPD \\
\hline $\mathrm{U} 75$ & Malig. neoplasm of kidney & ICPC & Description \\
\hline U76 & Malig. neoplasm of bladder & R95 & Chronic obstructive pulmonary dis \\
\hline U77 & Malig. neoplasm urinary other & R96 & Asthma \\
\hline U79 & Neoplasm urinary tract NOS & & \\
\hline $\mathrm{X} 75$ & Malig. neoplasm cervix & & \\
\hline $\mathrm{X} 76$ & Malig. neoplasm breast female & & \\
\hline $\mathrm{X} 77$ & Malig. neoplasm female genital oth & & \\
\hline X81 & Genital neoplasm female oth/unspec. & & \\
\hline Y77 & Malig. neoplasm prostate & & \\
\hline Y78 & Malig. neoplasm male genital oth & & \\
\hline
\end{tabular}

Abbreviations: COPD, chronic obstructive pulmonary disease; dis, disease; ICPC, International Classification of Primary Care; malig., malignant; NOS, not otherwise specified; oth, other; PVD, peripheral vascular disease; unspec., unspecified; w., with; w/o, without. 
Table A2. Frequency of Performed Diagnostic Interventions, Stratified by Sex and Reason for Encounter

\begin{tabular}{|c|c|c|c|c|}
\hline \multirow[b]{2}{*}{ Interventions } & \multicolumn{3}{|c|}{ Number of EoCs (\%) } & \multirow[b]{2}{*}{$P$ Value* } \\
\hline & Female & Male & Total & \\
\hline \multicolumn{5}{|c|}{ Interventions for headache $(\mathrm{N} 01 ; \mathrm{n}=3411)$} \\
\hline Physical examination & $1,615(75.0)$ & $977(77.6)$ & $2,592(76.0)$ & 0.09 \\
\hline Laboratory diagnostics & $255(11.8)$ & $154(12.2)$ & $409(12.0)$ & 0.74 \\
\hline Diagnostic imaging & $30(1.4)$ & $21(1.7)$ & $51(1.5)$ & 0.53 \\
\hline Referral to specialist & $223(10.4)$ & $141(11.2)$ & $364(10.7)$ & 0.45 \\
\hline \multicolumn{5}{|c|}{ Interventions for dizziness $(\mathrm{N} 17 ; \mathrm{n}=2709)$} \\
\hline Physical examination & $1,461(82.0)$ & $778(83.8)$ & $2,239(82.7)$ & 0.24 \\
\hline Laboratory diagnostics & $558(31.3)$ & $201(21.7)$ & $759(28.0)$ & $<0.001$ \\
\hline Diagnostic imaging & $10(0.6)$ & $9(1.0)$ & $19(0.7)$ & 0.23 \\
\hline Referral to specialist & $170(9.5)$ & $115(12.4)$ & $285(10.5)$ & 0.22 \\
\hline \multicolumn{5}{|c|}{ Interventions for heart pain $(\mathrm{K} 01 ; \mathrm{n}=660)$} \\
\hline Physical examination & $261(77.4)$ & $261(80.8)$ & $522(79.1)$ & 0.29 \\
\hline Laboratory diagnostics & $73(21.7)$ & $66(20.4)$ & $660(21.1)$ & 0.70 \\
\hline Diagnostic imaging & $6(1.8)$ & $7(2.2)$ & $13(2.0)$ & 0.72 \\
\hline Referral to specialist & $114(33.8)$ & $134(41.5)$ & $248(37.6)$ & 0.04 \\
\hline \multicolumn{5}{|c|}{ Interventions for (lower) back pain (L02/L03; $\mathrm{n}=5,962)$} \\
\hline Physical examination & $2,620(75.2)$ & $1,938(78.2)$ & $4,558(76.5)$ & $<0.01$ \\
\hline Laboratory diagnostics & $359(10.3)$ & $153(6.2)$ & $512(8.6)$ & $<0.001$ \\
\hline Diagnostic imaging & $502(14.4)$ & $339(13.7)$ & $841(14.1)$ & 0.43 \\
\hline Referral to specialist & $244(7.0)$ & $180(7.3)$ & $424(7.1)$ & 0.69 \\
\hline \multicolumn{5}{|c|}{ Interventions for nausea (D09; $\mathrm{n}=1222$ ) } \\
\hline Physical examination & $568(63.0)$ & $223(69.5)$ & $791(64.7)$ & 0.04 \\
\hline Laboratory diagnostics & $203(22.5)$ & $69(21.5)$ & $272(22.2)$ & 0.70 \\
\hline Diagnostic imaging & $34(3.8)$ & $10(3.1)$ & $44(3.6)$ & 0.59 \\
\hline Referral to specialist & $86(9.5)$ & $45(14.0)$ & $131(10.7)$ & 0.03 \\
\hline \multicolumn{5}{|c|}{ Interventions for muscle pain $(\mathrm{L} 18 ; \mathrm{n}=554)$} \\
\hline Physical examination & $219(68.0)$ & $171(73.7)$ & $390(70.4)$ & 0.15 \\
\hline Laboratory diagnostics & $98(30.4)$ & $79(34.1)$ & $177(31.9)$ & 0.37 \\
\hline Diagnostic imaging & $11(3.4)$ & $13(5.6)$ & $24(4.3)$ & 0.21 \\
\hline Referral to specialist & $36(11.2)$ & $22(9.5)$ & $58(10.5)$ & 0.52 \\
\hline \multicolumn{5}{|c|}{ Interventions for shortness of breath $(\mathrm{R} 02 ; \mathrm{n}=3,593)$} \\
\hline Physical examination & $1,903(90.6)$ & $1,375(92.1)$ & $3,278(91.2)$ & 0.12 \\
\hline Laboratory diagnostics & $559(26.6)$ & $376(25.2)$ & $935(26.0)$ & 0.33 \\
\hline Diagnostic imaging & $159(7.6)$ & $151(10.1)$ & $310(8.6)$ & $<0.01$ \\
\hline Referral to specialist & $302(14.4)$ & $263(17.6)$ & $565(15.7)$ & $<0.01$ \\
\hline \multicolumn{5}{|c|}{ Interventions for chills (A02; $\mathrm{n}=132$ ) } \\
\hline Physical examination & $39(58.2)$ & $54(83.1)$ & $93(70.5)$ & $<0.01$ \\
\hline Laboratory diagnostics & $20(29.9)$ & $16(24.6)$ & $36(27.3)$ & 0.50 \\
\hline Diagnostic imaging & $1(1.4 \%)$ & $1(1.5 \%)$ & $2(1.5 \%)$ & 0.98 \\
\hline Referral to specialist & $10(14.9)$ & $14(21.5)$ & $24(18.2)$ & 0.33 \\
\hline
\end{tabular}


Table A2. Continued

\begin{tabular}{|c|c|c|c|c|}
\hline \multirow[b]{2}{*}{ Interventions } & \multicolumn{3}{|c|}{ Number of EoCs (\%) } & \multirow[b]{2}{*}{$P$ Value* } \\
\hline & Female & Male & Total & \\
\hline \multicolumn{5}{|c|}{ Interventions for tingling in fingers, feet, and/or toes $(\mathrm{N} 05 ; \mathrm{n}=609)$} \\
\hline Physical examination & $311(85.2)$ & $204(83.6)$ & $515(84.6)$ & 0.59 \\
\hline Laboratory diagnostics & $72(19.7)$ & $55(22.5)$ & $127(20.9)$ & 0.40 \\
\hline Diagnostic imaging & $3(0.8)$ & $6(2.5)$ & $9(1.5)$ & 0.10 \\
\hline Referral to specialist & $61(16.7)$ & $33(13.5)$ & $94(15.4)$ & 0.29 \\
\hline \multicolumn{5}{|c|}{ Interventions for throat symptoms (D21/R21; $\mathrm{n}=4,961)$} \\
\hline Physical examination & $2,498(82.3)$ & $1,631(84.6)$ & $4,129(83.2)$ & 0.03 \\
\hline Laboratory diagnostics & $383(12.6)$ & $211(10.9)$ & $594(12.0)$ & 0.08 \\
\hline Diagnostic imaging & $36(1.2)$ & $25(1.3)$ & $61(1.2)$ & 0.73 \\
\hline Referral to specialist & $243(8.0)$ & $165(8.6)$ & $408(8.2)$ & 0.49 \\
\hline \multicolumn{5}{|c|}{ Interventions for weakness $(\mathrm{A} 04 ; \mathrm{n}=5,608)$} \\
\hline Physical examination & $2,599(70.4)$ & $1,467(76.6)$ & $4,066(72.5)$ & $<0.001$ \\
\hline Laboratory diagnostics & $2,759(74.7)$ & $1,311(68.5)$ & $4,070(72.6)$ & $<0.001$ \\
\hline Diagnostic imaging & $104(2.8)$ & $73(3.8)$ & $177(3.2)$ & 0.04 \\
\hline Referral to specialist & $284(7.7)$ & $200(10.4)$ & $484(8.6)$ & $<0.001$ \\
\hline \multicolumn{5}{|c|}{ Interventions for arm and leg symptoms (L09/L14; $\mathrm{n}=4,847$ ) } \\
\hline Physical examination & $2,408(86.4)$ & $1,797(87.2)$ & $4,205(86.8)$ & 0.40 \\
\hline Laboratory diagnostics & $310(11.1)$ & $184(8.9)$ & $494(10.2)$ & $<0.01$ \\
\hline Diagnostic imaging & $368(13.2)$ & $296(14.4)$ & $552(11.4)$ & 0.24 \\
\hline Referral to specialist & $387(13.9)$ & $299(14.5)$ & $686(14.2)$ & 0.54 \\
\hline \multicolumn{5}{|c|}{ Interventions for all RFE $(\mathrm{n}=34,268)$} \\
\hline Physical examination & $16,502(78.5)$ & $10,876(82.1)$ & $27,378(79.9)$ & $<0.001$ \\
\hline Laboratory diagnostics & $5,649(26.9)$ & $2,875(21.7)$ & $8,524(24.9)$ & $<0.001$ \\
\hline Diagnostic imaging & $1,264(6.0)$ & $951(7.2)$ & $2,215(6.5)$ & $<0.001$ \\
\hline Referral to specialist & $2,160(10.3)$ & $1,611(12.2)$ & $3,771(11.0)$ & $<0.001$ \\
\hline
\end{tabular}

Abbreviations: EoC, episode of care; RFE reason for encounter. ${ }^{*} \chi^{2}$ test. 


\section{Appendix 3}

Table A3. Significant Diagnostic Intervention-by-Female-Sex Interaction Terms

\begin{tabular}{|c|c|c|c|c|}
\hline \multirow[b]{2}{*}{ Independent Variables } & \multicolumn{4}{|c|}{ OR $(95 \% \mathrm{CI})^{*}$} \\
\hline & $\begin{array}{l}\text { Headache } \\
(\mathrm{n}=3411)\end{array}$ & $\begin{array}{l}\text { Dizziness } \\
(\mathrm{n}=2709)\end{array}$ & $\begin{array}{c}\text { Heart Pain } \\
(\mathrm{n}=660)\end{array}$ & $\begin{array}{l}\text { (Lower) Back Pain } \\
\quad(\mathrm{n}=5962)\end{array}$ \\
\hline Physical examination & ns & ns & ns & $0.51(0.34-0.78)$ \\
\hline Laboratory diagnostics & ns & ns & ns & ns \\
\hline Imaging & ns & ns & ns & $0.64(0.43-0.96)$ \\
\hline \multirow[t]{3}{*}{ Specialist referral } & ns & ns & $0.39(0.17-0.90)$ & $0.46(0.29-0.72)$ \\
\hline & \multicolumn{4}{|c|}{ OR $(95 \% \mathrm{CI})^{*}$} \\
\hline & $\begin{array}{l}\text { Nausea } \\
(\mathrm{n}=1222)\end{array}$ & $\begin{array}{l}\text { Muscle Pain } \\
(\mathrm{n}=554)\end{array}$ & $\begin{array}{l}\text { Shortness of Breath } \\
\qquad(\mathrm{n}=3593)\end{array}$ & $\begin{array}{c}\text { Chills } \\
(\mathrm{n}=132)\end{array}$ \\
\hline Physical examination & ns & ns & ns & ns \\
\hline Laboratory diagnostics & ns & ns & ns & ns \\
\hline Imaging & ns & ns & ns & ns \\
\hline \multirow[t]{3}{*}{ Specialist referral } & ns & ns & ns & ns \\
\hline & \multicolumn{4}{|c|}{ OR $(95 \% \mathrm{CI})^{*}$} \\
\hline & $\begin{array}{c}\text { Tingling in Fingers, } \\
\text { Feet, and/or Toes }(\mathrm{n}=609)\end{array}$ & $\begin{array}{l}\text { Swallowing/Throat } \\
\text { Symptoms }(\mathrm{n}=4961)\end{array}$ & $\begin{array}{l}\text { Weakness/General } \\
\text { Tiredness }(\mathrm{n}=5608)\end{array}$ & $\begin{array}{c}\text { Arm and/or Leg } \\
\text { Symptoms }(n=4847)\end{array}$ \\
\hline Physical examination & $\mathrm{ns}$ & ns & ns & ns \\
\hline Laboratory diagnostics & $0.32(0.13-0.81)$ & ns & $0.72(0.53-0.96)$ & $0.56(0.37-0.86)$ \\
\hline Imaging & $\mathrm{ns}$ & ns & ns & ns \\
\hline Specialist referral & ns & ns & ns & $0.65(0.46-0.92)$ \\
\hline
\end{tabular}

Abbreviations: OR, odds ratio; CI, confidence interval.

aAdjusted for the patients' age at diagnosis, comorbidities, number of contacts per EoC, and sex. 